\title{
Uniparental disomy 7 in Silver-Russell syndrome and primordial growth retardation
}

Kotzot, Dieter ; Schmitt, Silke ; Bernasconi, Fabiana ; Robinson, Wendy P ; Lurie, Iosif W ; Ilyina, Helena ; Méhes, Károly ; Hamel, Ben C J ; Otten, Barto J ; Hergersberg, Martin ; Werder, Edmond ; Schoenle, Eugen ; Schinzel, Albert

\begin{abstract}
Maternal uniparental disomy for the entire chromosome 7 has so far been reported in three patients with intrauterine and postnatal growth retardation. Two were detected because they were homozygous for a cystic fibrosis mutation for which only the mother was heterozygous, and one because he was homozygous for a rare COL1A2 mutation. We investigated 35 patients with either the Silver-Russell syndrome or primordial growth retardation and their parents with PCR markers to search for uniparental disomy 7 . Four of 35 patients were found to have maternal disomy, including three with isodisomy and one with heterodisomy. The data confirm the hypothetical localization of a maternally imprinted gene (or more than one such gene) on chromosome 7. It is suggested to search for UPD 7 in families with an offspring with sporadic Silver-Russell syndrome or primordial growth retardation
\end{abstract}

DOI: https://doi.org/10.1093/hmg/4.4.583

Posted at the Zurich Open Repository and Archive, University of Zurich

ZORA URL: https://doi.org/10.5167/uzh-154293

Journal Article

Published Version

Originally published at:

Kotzot, Dieter; Schmitt, Silke; Bernasconi, Fabiana; Robinson, Wendy P; Lurie, Iosif W; Ilyina, Helena; Méhes, Károly; Hamel, Ben C J; Otten, Barto J; Hergersberg, Martin; Werder, Edmond; Schoenle, Eugen; Schinzel, Albert (1995). Uniparental disomy 7 in Silver-Russell syndrome and primordial growth retardation. Human Molecular Genetics, 4(4):583-587.

DOI: https://doi.org/10.1093/hmg/4.4.583 


\title{
Uniparental disomy 7 in Silver-Russell syndrome and primordial growth retardation
}

\author{
Dieter Kotzot, Silke Schmitt ${ }^{1}$, Fabiana Bernasconi, Wendy P.Robinson, losif W.Lurie ${ }^{2}$, \\ Helena llyina², Károly Méhes ${ }^{3}$, Ben C.J.Hamel ${ }^{4}$, Barto J.Otten ${ }^{5}$, Martin Hergersberg, \\ Edmond Werder ${ }^{1}$, Eugen Schoenle ${ }^{1}$ and Albert Schinzel*
}

Institute of Medical Genetics, University of Zürich, Rämistr. 74, CH-8001, 'Department of Pediatrics, University of Zürich, Zürich, Switzerland, 2 Institute for Hereditary Diseases, Minsk, Belarus, ${ }^{3}$ Department of Pediatrics, University of Pécs, Hungary, Departments of ${ }^{4}$ Human Genetics and ${ }^{5}$ Pediatrics, University Hospital Nijmegen, Nijmegen, The Netherlands

Received December 6, 1994; Accepted January 9, 1995

\begin{abstract}
Maternal uniparental disomy for the entire chromosome 7 has so far been reported in three patients with intrauterine and postnatal growth retardation. Two were detected because they were homozygous for a cystic fibrosis mutation for which only the mother was heterozygous, and one because he was homozygous for a rare COL1A2 mutation. We investigated 35 patients with either the Silver-Russell syndrome or primordial growth retardation and their parents with PCR markers to search for uniparental disomy 7 . Four of 35 patients were found to have maternal disomy, including three with isodisomy and one with heterodisomy. The data confirm the hypothetical localization of a maternally imprinted gene (or more than one such gene) on chromosome 7. It is suggested to search for UPD 7 in families with an offspring with sporadic Silver-Russell syndrome or primordial growth retardation.
\end{abstract}

\section{INTRODUCTION}

Uniparental disomy (UPD), the inheritance of both homologous chromosomes from only one parent, has been found in some individuals with: (i) balanced interhomologous rearrangements (1); (ii) autosomal recessive disorders (2-7); (iii) fetuses or newborns after the determination of confined placental mosaicism (8-11); and (iv) in a proportion of patients with the Prader-Willi syndrome and the Angelman syndrome (1215). In these two syndromes, the loss of the active homologue of one or several imprinted genes is considered to be responsible for the developmental anomalies. Segmental or mosaic paternal UPD 11 was found in a minority of cases with the Wiedemann-Beckwith syndrome (4,16-18). Excess IGF2 expression caused by two active IGF2 gene copies is suggested to be responsible for the latter syndrome. In mice, as in humans, the Igf2 gene is maternally and the H19 gene paternally imprinted $(19,20)$. Both genes map to distal murine chromosome 7 which is partially homologous to the human chromosome 11. It has been demonstrated that murine paternal disomy 7 and hence overexpression of the Igf 2 gene and lack of expression of the HI9 gene leads to fetal overgrowth while maternal disomy causes lack of expression of the Igf 2 gene and thus results in intrauterine growth retardation (review in reference 21 ).

In humans, primordial growth retardation (PGR) is characterized by prenatal as well as postnatal growth retardation. If no associated findings are present, it is considered to be PGR sensu stricto. PGR, however, can be a feature of a number of syndromes of known or unknown etiology; most of them are associated with mental deficiency. Examples include the fetal alcohol syndrome (FAS), the autosomal recessively inherited Bloom and Dubowitz syndromes and the Silver-Russell syndrome (SRS; 22-24). The latter syndrome predominantly occurs sporadically, although some instances of direct transmission from a parent to one child or several children (25) and of siblings born to unaffected parents (26) have been reported. In addition to PGR, the SRS is characterized by a disproportionately large head with a broad and prominent forehead and a small and narrow lower portion of the face giving it a triangular appearance, delayed closure of the anterior fontanelle, downturned corners of the mouth, hemihypotrophy of face, trunk and limbs, clinodactyly and brachymesophalangy of little fingers, partial cutaneous syndactyly between second and third toes, areas of hypo- or hyperpigmentation of the skin, male genital hypoplasia, diminished subcutaneous tissue, delayed bone maturation and excessive sweating, especially over the forehead. None of these features is obligatory. Motor and mental development are normal in the majority of cases.

Three instances of maternal $(2,3,27)$, one instance of maternal long arm and paternal short arm (28) and one instance of paternal UPD 7 (7) have recently been reported. All four

*To whom correspondence should be addressed 
maternal UPD cases were growth-retarded whereas the one with paternal isodisomy was not growth-retarded and was detected upon molecular investigation of a family with a proband with congenital chloride diarrhea who did not reveal growth retardation. Two isodisomic patients were discovered at molecular investigation of families with probands with cystic fibrosis $(\mathrm{CF})$. Loci around the CF locus were found to be exclusively maternally derived as were all other investigated loci elsewhere on chromosome 7. Both patients displayed severe pre- and postnatal growth retardation which could not be sufficiently explained as a consequence of CF (2,3). A third patient, with maternal partial heterodisomy and partial isodisomy 7, was ascertained at molecular investigation for the COL1A2 locus for which he was homozygous (27). A fourth patient (28) was born at term with a normal weight and length, but subsequently became growth-retarded. At 2 years 3 months of age, she revealed slight limb asymmetry, a triangular face and bilateral clinodactyly of little fingers; psychomotor development was normal. On cytogenetic examination, the two no. 7 chromosomes were replaced by two metacentric chromosomes, an isochromosome $7 \mathrm{p}$ and an isochromosome $7 \mathrm{q}$. Molecular investigation revealed paternal isodisomy for $7 \mathrm{p}$ and maternal isodisomy for $7 \mathrm{q}$. This patient

a

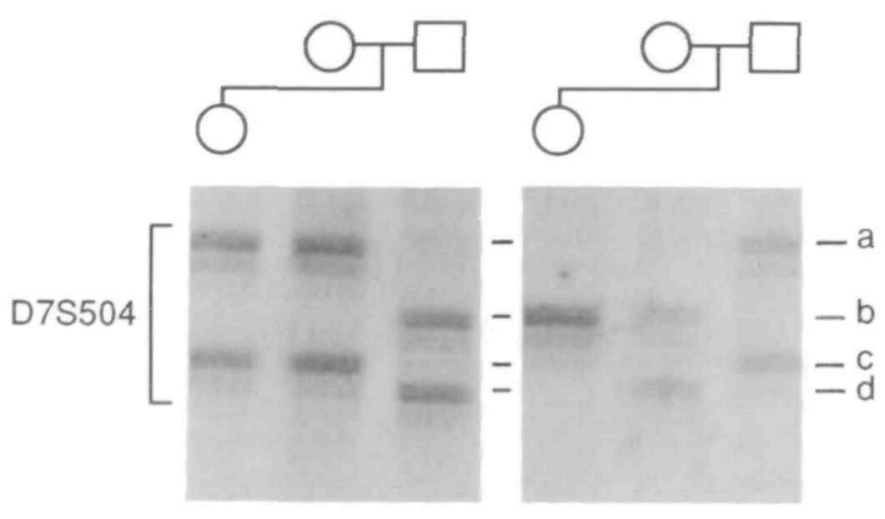

b

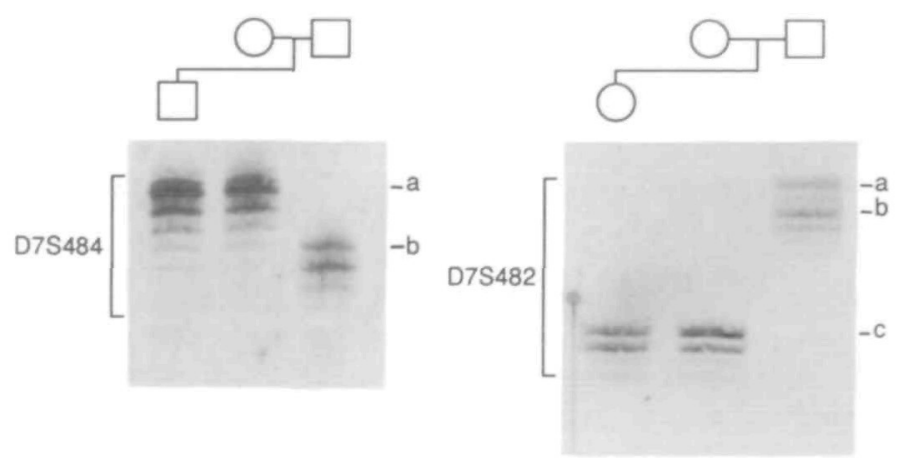

Figure 1. (a) Results for D7S504. Left: Patient 2 has inherited the maternal alleles ' $a$ ' and ' $c$ ', but failed to inherit any of the two paternal alleles ' $b$ ' and 'd'. Right: Patient 4 has inherited a double dose of one of the maternal alleles ('b'), but failed to inherit any of the paternal alleles ' $a$ ' and ' $c$ '. (b) Left: D7S484. Patient 1 has inherited the maternal allele ' $a$ ', but not the paternal allele ' $b$ '. Right: D7S482. Patient 3 has inherited the maternal allele ' $c$ ', but none of the two paternal alleles ' $a$ ' and ' $b$ '. is the only of four without intrauterine growth retardation as well as the only who is maternally disomic for only the long arm of chromosome 7 . The authors concluded that normal prenatal growth requires expression of a paternal gene on $7 p$ while postnatal growth deficit could be due to the lack of expression of a paternally derived gene on $7 q$ (28). However, as the rearrangement leading to disomy in this case must have occurred postmeiotically, it could have been confined to the fetus. Dysfunction of the placenta due to aneuploidy could explain the prenatal growth retardation in the other cases, and therefore one does not need to hypothesize two imprinted genes. The putative maternally imprinted postnatal growth retardation gene must still lie on the $\mathrm{q}$ arm since the Eggerding patient was only disomic for maternal $7 q$. However, all the candidate genes lie on the $\mathrm{p}$ arm. Perhaps there really is an imprinted prenatal growth retardation gene on $7 p$ in which case one of these would be a candidate.

In order to determine whether maternal UPD 7 might be the cause of a significant proportion of patients with PGR and SRS, we investigated two series of patients with their parents with PCR markers for uniparental disomy 7: (i) 25 cases with sporadic SRS; (ii) 10 patients with PGR. We found maternal UPD 7 in four patients of the 35 patients investigated including three of 25 with SRS and one of 10 with PGR.

\section{RESULTS}

\section{The study population}

The study population consisted of 35 families with an offspring with either the SRS $(n=25)$ or PGR $(n=10)$, both of sporadic occurrence. Probands with chromosome aberrations and other, genetic and non-genetic causes for intrauterine growth retardation were excluded from the study population. In three families it was not possible to obtain blood from both parents. Ages of the probands ranged between 1 year 2 months and 16 years 9 months at examination.

\section{Markers on chromosome 7}

In four families, marker analysis revealed maternal UPD 7 (Table 1 and Fig. 1a,b). Patients 1, 3 and 4 were homozygous for all informative markers ( 7,14 and 11 , respectively) while patient 2 showed heterodisomy, inheritance of two different maternal alleles, for D7S504 and D7S640. At another informative locus (D7S489b), mother and child were homozygous for the $b$ allele while the father was homozygous for the a allele. In addition, patient 2 had inherited maternal heterozygosity at 15 markers; there was no marker in whom the proband differed from the mother in terms of reduction to homozygosity. In patients 1, 3 and 4 the numbers of loci showing reduction of maternal heterozygosity to homozygosity were 6,12 and 10 , respectively, and the numbers of loci showing lack of inheritance of a paternal allele in the proband, but being uninformative for maternal homo- versus heterozygosity were 1,2 and 1, respectively. Analysis of additional microsatellite markers on chromosomes 6, 11 and 15 revealed no evidence for nonpaternity in any of the four patients.

The other 32 patients showed normal biparental inheritance for at least one informative marker on chromosome 7.

\section{The four uniparental disomy 7 patients}

Patients 1-3 were clinically classified as having the SRS before the investigations were performed while patient 4 was 
considered to have PGR, but not the full SRS picture. Patients 1,3 and 4 (all with isodisomy) were born to parents below 35 years of age while parental ages of patient 2 (with heterodisomy) were 39 years for the mother and 35 years for the father. Birth weight and length were below the third percentile for gestational age in all patients. Ages at examination ranged from 19 months (patient 1) to 8 years 6 months (patient 3). Length/height at last examination ranged between 3 and 5.5 SD below the mean. Psychomotor development was considered normal in all four patients. Patients 1-3 displayed the full spectrum of the SRS including the characteristic facies; however, patient 4 , referred with the diagnosis of primordial growth retardation, also displayed the following SRS features: a triangular face with broad forehead and prominent philtrum and lips; short fifth fingers with clinodactyly; excessive sweating over the forehead; mild limb asymmetry; and a grossly retarded bone age.

\section{DISCUSSION}

Maternal uniparental disomy 7 was found in four of 35 cases with PGR (including 25 diagnosed with the SRS phenotype). This increases the number of published cases with full maternal UPD 7 to seven, and that of maternal UPD for the long arm of chromosome 7 to eight. Of these cases, the molecular results were compatible with complete maternal isodisomy in five $(2,3$; patients 1,3 and 4 of the present study). These cases are most likely the result of a postzygotic mitotic nondisjunction of the maternal chromosome 7 and loss at any stage (premeiotically, meiotically or postmeiotically) of the paternal homolog. The results in one case (patient 2 of the present study) disclosed complete heterodisomy which would indicate meiosis 1 nondisjunction of chromosome 7 in an 'older' mother, possibly with lack of pairing and recombination. Long arm and proximal short arm homozygosity, but distal short

Table 1. Results of PCR marker analysis in the four probands with maternal UPD 7 and their parents

\begin{tabular}{|c|c|c|c|c|}
\hline Microsatellite & Case 1 & Case 2 & Case 3 & Case 4 \\
\hline D7S481 & $\mathbf{b} / \mathbf{a b} / \mathbf{c d}$ & $\mathrm{b} / \mathrm{b} / \mathrm{ab}$ & $\mathrm{c} / \mathrm{bc} / \mathrm{ac}$ & $\mathrm{d} / \mathrm{cd} / \mathbf{a b}$ \\
\hline D7S507 & $\mathbf{a} / \mathbf{a b} / \mathbf{b}$ & $\mathrm{ac} / \mathrm{ac} / \mathrm{ab}$ & $\mathrm{d} / \mathrm{ad} / \mathrm{bc}$ & $\mathrm{b} / \mathrm{ab} / \mathrm{ab}$ \\
\hline D7S503 & $\mathbf{b} / \mathbf{b d} / \mathbf{a c}$ & $a b / a b / a b$ & b/bd/ac & $a / a / a b$ \\
\hline D7S488 & & $a b / a b / a c$ & c/bc/ab & $a / a b / a b$ \\
\hline D7S435 & $\mathrm{a} / \mathrm{ab} / \mathrm{ac}$ & $\mathrm{b} / \mathrm{b} / \mathrm{ab}$ & $\mathrm{c} / \mathrm{cd} / \mathbf{a b}$ & $\mathbf{a} / \mathbf{a} / \mathbf{b}$ \\
\hline D7S460 & $\mathrm{b} / \mathrm{ab} / \mathrm{b}$ & $a b / a b / b c$ & $\mathbf{a} / \mathbf{a c} / \mathbf{b c}$ & $\mathbf{b} / \mathbf{a b} / \mathbf{c}$ \\
\hline D7S484 & $\mathbf{a} / \mathbf{a} / \mathbf{b}$ & $a b / a b / b$ & $\mathrm{c} / \mathrm{bc} / \mathrm{ac}$ & $\mathrm{c} / \mathrm{cd} / \mathrm{ab}$ \\
\hline EGFR & $\mathrm{a} / \mathrm{ab} / \mathrm{ac}$ & $a b / a b /$ & & \\
\hline D7S482 & $\mathrm{a} / \mathrm{ab} / \mathrm{ac}$ & $\mathrm{b} / \mathrm{b} / \mathrm{ab}$ & c/c/ab & $\mathbf{b} / \mathbf{a b} / \mathbf{a}$ \\
\hline ELN & b/ab/ab & $b / b / a b$ & $b / a b / a b$ & $a / a b / a b$ \\
\hline D7S489a & $\mathrm{b} / \mathrm{ab} / \mathrm{bc}$ & $a / a / a b$ & $\mathrm{~b} / \mathrm{bc} / \mathrm{ab}$ & $a / a / a b$ \\
\hline D7S489b & $\mathbf{a} / \mathbf{a b} / \mathbf{a b}$ & $\mathbf{b} / \mathbf{b} / \mathbf{a}$ & $a / a b / a b$ & $\mathbf{b} / \mathbf{a b} / \mathbf{a}$ \\
\hline D7S440 & $\mathrm{b} / \mathrm{ab} / \mathrm{b}$ & $\mathrm{a} / \mathrm{a} / \mathrm{ab}$ & $\mathbf{b} / \mathbf{a b} / \mathbf{a}$ & $a / a b / a$ \\
\hline D7S524 & $a / a / a b$ & $a b / a b / b$ & $\mathrm{~b} / \mathrm{b} / \mathrm{ab}$ & $\mathbf{a} / \mathbf{a c} / \mathbf{b}$ \\
\hline D7S492 & $\mathrm{a} / \mathrm{ac} / \mathrm{ab}$ & $a b / a b / a b$ & $\mathbf{a} / \mathbf{a} / \mathbf{b c}$ & $\mathrm{b} / \mathrm{b} / \mathrm{ab}$ \\
\hline D7S479 & c/ac/ab & $\mathrm{b} / \mathrm{b} / \mathrm{ab}$ & b/bc/ad & $a / a / a b$ \\
\hline D7S 527 & $\mathbf{a} / \mathbf{a} / \mathbf{a}$ & $a b / a b / b$ & $a / a / a b$ & $\mathbf{a} / \mathbf{a b} / \mathbf{b}$ \\
\hline D7S504 & $\mathbf{b} / \mathbf{b c} / \mathbf{a}$ & ac/ac/bd & $\mathrm{c} / \mathrm{bc} / \mathrm{ac}$ & $\mathrm{b} / \mathrm{bd} / \mathbf{a c}$ \\
\hline D7S640 & c/ac/b & $\mathrm{ab} / \mathrm{ab} / \mathrm{cd}$ & b/ab/c & $\mathrm{c} / \mathrm{ac} / \mathrm{bc}$ \\
\hline CFtR-8CA & $\mathrm{b} / \mathrm{b} / \mathrm{ab}$ & $a b / a b / b$ & $\mathrm{~b} / \mathrm{b} / \mathrm{ab}$ & $\mathrm{a} / \mathrm{a} / \mathrm{a}$ \\
\hline D7S550 & $\mathrm{b} / \mathrm{ab} / \mathrm{ab}$ & $a b / a b / a b$ & c/ac/b & $\mathrm{a} / \mathrm{ad} / \mathrm{c}$ \\
\hline D7S559 & $\mathrm{c} / \mathrm{c} / \mathrm{ac}$ & $a b / a b / a b$ & c/bc/a & $\mathbf{b} / \mathbf{a b} / \mathbf{a}$ \\
\hline D7S594 & $\mathrm{b} / \mathrm{ab} / \mathrm{bc}$ & $\mathrm{a} / \mathrm{a} / \mathrm{a}$ & c/bc/a & $\mathrm{b} / \mathrm{bc} / \mathrm{ab}$ \\
\hline D7S396 & $b / a b / a b$ & $\mathrm{bc} / \mathrm{bc} / \mathrm{ac}$ & $\mathbf{a} / \mathbf{a c} / \mathbf{b c}$ & $\mathrm{c} / \mathrm{ac} / \mathrm{bc}$ \\
\hline
\end{tabular}

Order of alleles: proband/mother/father. Informative markers are in bold. arm heterozygosity of chromosome 7 markers would indicate meiosis 2 nondisjunction following recombination at $7 p$ at meiosis 1 in the patient of Spotila et al. (27). The mechanism in the case of Eggerding et al. (28) with two isochromosomes, one, paternally derived, for $7 p$ and the other, maternally derived, for $7 \mathrm{q}$, is again different and complete homozygosity indicates postmeiotic origin of a structural rearrangement between the two chromosomes 7 .

The present findings confirm that maternal UPD 7 is a cause of PGR, especially of the SRS-type, in a significant number of cases. Out of the four 'positive' cases of the present study, three had been classified as having the SRS while one (patient 4) was considered to have 'simple' PGR. However, the classification of SRS in patients with PGR is subjective, and as patient 4 exhibited some features beyond PGR which are also found in SRS (triangular facies, broad forehead, clinodactyly), it is possible that other clinicians would have classified her as a case of SRS. Clinically, the four UPD 7positive patients do not differ in any way from the 31 other cases in whom UPD 7 was excluded.

In the 14 year old patient of Spence et al. (2) with maternal isodisomy 7 and cystic fibrosis, asymmetry of the legs was noticed, and the diagnosis of SRS was discussed, although she did not show the characteristic facies. Abnormal findings beyond growth retardation were not mentioned by Voss et al. (3). The patient of Spotila et al. (1992) was a 30 year old male who was mentioned to have had a pointed face at age 1 year. This might indicate an SRS-like facies. As the facies of SRS patients tend to become more normal with age and especially in adulthood, a (partial) SRS-like phenotype can probably not be excluded. Finally, Eggerding et al. (28) described SRS-features such as a triangular facies, bilateral clinodactyly of little fingers and slight limb asymmetry, in a 27 month old girl without mentioning SRS. Thus, the patients so far observed with maternal UPD 7 seem to have PGR with a mild or incomplete SRS phenotype. However, it cannot be excluded that maternal UPD 7 may cause 'pure' PGR without additional abnormalities in some instances. It seems very unlikely that undetected mosaicism for trisomy 7 in the probands could cause growth retardation without mental retardation and variable other features, and it is excluded in the case with two isochromosomes (28) who could not have arisen through an initial trisomy.

The results of our investigation lend further support to the hypothesis already expressed by Voss et al. (3) and Spotila et al. (27) that there is at least one matemally imprinted gene on chromosome 7 which controls intrauterine and postnatal growth. Patients with maternal UPD 7 obviously have PGR with additional varying features of SRS. Although the number of investigated patients with SRS/PGR is still small, we judge that approximately $10 \%$ of sporadic patients with isolated PGR \pm SRS features and no evidence for another etiology might result from maternal UPD 7 . Thus, it is probably justified to investigate families with a sporadic offspring with PGR or SRS for UPD 7. Further indication for this etiology would be increased maternal age as in patient 2 , the only case so far observed due to maternal meiosis 1 nondisjunction. This observation, in addition to the lack of any non-growth-retarded cases with maternal UPD 7, is a strong argument against reduction to homozygosity of a non-imprinted recessive gene as the cause of PGR in these probands. A review of genes mapping to human chromosome 7 reveals that the epidermal 
growth factor receptor gene (EGFR) maps to the short arm of chromosome 7 (29,30; Genome Database 1994). Its imprinting status in humans seemingly has not yet been studied. Thus, EGFR could be a candidate gene to cause growth retardation in maternal UPD 7. Furthermore, insulin-like growth factor binding proteins 1 and 3 (IGFBP-1 and IGFBP-3) both map to the short arm of chromosome 7 and have been suggested to regulate cell growth (31)

It is very likely that SRS is genetically heterogeneous. If, as our data suggest, loss or mutations of a maternally imprinted gene or genes account for a proportion of cases with this phenotype, one would then expect that mutations or microdeletions of that gene(s) or of the imprinting region could be responsible for an additional proportion of cases with SRS. As SRS patients are not necessarily infertile, this would imply that microdeletions or mutations could be transmitted in a dominant fashion from a father to one or two of his offspring. If the father would have inherited the mutation from his father, he would also show the SRS phenotype while he would be normal, and thus the pedigree be suggestive of recessive inheritance, if he had received the mutation from his mother. The same would be true for mutations which would falsely activate the imprinting process on the paternal allele. A linkage study of such families with chromosome 7 markers could help to narrow down the localization of such a gene or genes to one or several smaller regions of that chromosome. However, if, as it seems to be in the Prader-Willi syndrome, there is a series of genes involved in the phenotype, it would be less likely to find such pedigrees.

To summarize, using PCR marker analysis, we found four patients with maternal UPD 7 among 35 patients with PGR or SRS. This high incidence justifies that an investigation of UPD 7 should be performed in patients with sporadic PGR or SRS without further features or another etiology.

\section{MATERIALS AND METHODS}

Cytogenetic examinations were performed in the probands on blood lymphocyte cultures. GTG banded preparations were investigated, on the average 10 metaphases per case on the level of 400 bands.

DNA was extracted from blood samples as previously described (32), and microsatellite loci in the probands and their parents were analyzed using the polymerase chain reaction. In three families only one parent was available. A total of 27 microsatellite loci and one RFLP marker from chromosome 7 were studied. In addition, microsatellite loci from chromosomes 6,11 and 15 were studied in order to exclude non-paternity. A complete description of the allele frequencies and primers or probes used to detect the loci is available from the Genome Data Base.

\section{ACKNOWLEDGMENTS}

This project was supported by the Swiss National Foundation (grant no. 3237798.93 to AS), the EMBO, Heidelberg (grant to DK), the Roche Research Foundation (SS and ES), the Julius Müller Stiftung, Zürich (SS and ES), the Stiftung zur Krebsbekämpfung, Zürich (SS and ES), and the Deutsche Forschungsgemeinschaft (DFG grant Schm 943/1-1 to SS). We express our gratitude to all the referring physicians, the patients and their parents.

\section{ABBREVIATIONS}

CF, cystic fibrosis; IGF, insulin-like growth factor; PCR, polymerase chain reaction; PGR, primordial growth retardation; SRS, Silver-Russell syndrome; SD, standard deviation; UPD, uniparental disomy.

\section{REFERENCES}

1. Robinson W.P., Bernasconi F., Basaran S., Yüksel-Apak M., Neri G. Serville F., Balicek P., Haluza R., Farah L.M.S., Lüleci G., Schinzel A.A. (1994) A somatic origin of homologous Robertsonian translocations and isochromosomes. Am J Hum Genet 54: 290-302.

2. Spence J.E., Perciaccante R.G., Greig G.M., Huntington F.W., Ledbetter D.H., Hejtmancik J.F., Pollack M.S., O'Brien W.E., Beaudet A.L. (1989) Uniparental disomy as a mechanism for human genetic disease. Am J Hum Genet 42: 217-226.

3. Voss R., Ben-Simon E., Avital A., Godrey S., Zlotogora J., Dagan J., Tikochinski Y., Hillel J. (1989) Isodisomy for chromosome 7 in a patient with cystic fibrosis: Could uniparental disomy be common in humans? Am J Hum Genet 45: 373-380.

4. Beldjord C., Henry I., Bennani C., Vanhaeke D., Labie D. (1992) Uniparental disomy: a novel mechanism for thalassemia major. Blood 80: 287-289.

5. Pentao L., Lewis R.A., Ledbetter D.H., Patel P.I., Lupski J.R. (1992) Maternal uniparental isodisomy of chromosome 14: association with autosomal recessive rod monochromacy. Am J Hum Genet 50: 690-699.

6. Woodage T., Prasad M., Dixon J.W., et al. (1994) Bloom syndrome and maternal uniparental disomy for chromosome 15. Am J Hum Genet 55: 74-80.

7. Hoglund P., Holmberg C., de la Chapelle A., Kere J. (1994) Paternal isodisomy for chromosome 7 is compatible with normal growth and development in a patient with congenital chloride diarrhea. Am J Hum Genet 55: 747-752.

8. Purvis-Smith S.G., Saville T., Manass S., Yip M.Y., Lam-Po-Tang P.R.L., Duffy B., Johnston H., Leigh D., McDonald B. (1992) Uniparental disomy 15 resulting from 'correction' of an initial trisomy 15. Am J Hum Genet 50: 1348-1350.

9. Cassidy S.B., Lai L.W., Erickson R.P., Magnuson L., Thomas E., Gendron R., Herrmann J. (1992) Trisomy 15 with loss of the paternal 15 as a cause of Prader-Willi syndrome due to maternal disomy. Am J Hum Genet 51: 701-708.

10. Kalousek D.K., Langlois S., Barrett I., Yam I., Wilson D.R., HowardPeebles P.N., Johnson M.P., Giorgiutti E. (1993) Uniparental disomy for chromosome 16 in humans. Am J Hum Genet 52: 8-16.

11. Vaughan J., Ali Z., Bower S., Bennett P., Chard T., Moore G. (1994) Human maternal uniparental disomy for chromosome 16 and fetal development. Prenat Diagn 14: 751-756.

12. Nicholls R.D., Knoll J.H.M., Butler M.G., Karam S., LaLande M. (1989) Genetic imprinting suggested by maternal heterodisomy in non-deletion Prader-Willi syndrome. Nature 342: 281-285.

13. Malcolm S., Clayton-Smith J., Nichols M., Robb S., Webb T., Armour J.A.L., Jeffreys A.J., Pembrey M.E. (1991) Uniparental disomy in Angelman's syndrome. Lancet 337: 694-697.

14. Robinson W.P., Bottani A., Yagang X., Balakrishnan J., Binkert F., Mächler M., Prader A., Schinzel A.A. (1991) Molecular, cytogenetic, and clinical investigations of Prader-Willi syndrome patients. Am J Hum Genet 49: 1219-1234.

15. Bottani A., Robinson W.P., DeLozier-Blanchet C., Engel E., Morris M., Schmitt B., Thun-Hohenstein L., Schinzel A. (1994) Angelman syndrome due to paternal uniparental disomy of chromosome 15: a milder phenotype? Am J Med Genet 51:35-40.

16. Henry I., Bonaiti-Pellié C., Chéhensse V., Beldjord C., Schwartz C., Utermann G., Junien C. (1991) Uniparental paternal isodisomy in a genetic cancer-predisposing syndrome. Nature 351: 665-667.

17. Henry I., Puech A., Riesewijk A., Ahnine L., Mannens M., Beldjord C., Bitoun P., Tournade M.F., Landrieu P., Junien C. (1993) Somatic mosaicism for partial paternal isodisomy in Wiedemann-Beckwith syndrome: a post-fertilization event. Eur J Hum Genet 1: 19-29.

18. Slatter R.E., Elliott M., Welham K., Carrera M., Schofield P.N., Barton D.E., Maher E.R. (1994) Mosaic uniparental disomy in BeckwithWiedemann syndrome. J Med Genet 31: 749-753.

19. Bartolomei M.S., Zemel S., Tilghman S.M. (1991) Parental imprinting of the mouse H19 gene. Nature 351: 153-155.

20. DeChiara T.M., Robertson E.J., Efstratiadis A. (1991) Parental imprinting of the mouse insulin-like growth factor II gene. Cell 64: 849-859.

21. Cattanach B.M., Jones J. (1994) Genetic imprinting in the mouse: implications for gene regulation. J Inher Metab Dis 17: 403-420.

22. Silver H.K., Kiyasu W., George J., Deamer C. (1953) Syndrome of congenital hemihypertrophy, shortness of stature, and elevated urinary gonadotropins. Pediatrics 12: 368-376. 
24. Tanner J.M., Lejarrage H., Cameron N. (1975) The natural history of the Silver-Russell syndrome: a longitudinal study of thirty-nine cases. Pediatr Res 9: 611-623.

23. Russell A. (1954) A syndrome of 'intra-uterine dwarfism' recognizable at birth with craniofacial dysostosis, disproportionately short arms, and other anomalies. Proc R Soc Med 47: 1040-1044.

25. Duncan P.A., Hall J.G., Shapiro L.R., Vibert B.K. (1990) Three-generation dominant transmission of the Silver-Russell syndrome. Am J Med Genet 35: $245-250$.

26. Teebi A.S. (1992) Autosomal recessive Silver-Russell syndrome. Clin Dysmorph 1: 151-156.

27. Spotila L.D., Sereda L., Prockop D.J. (1992) Partial isodisomy for maternal chromosome 7 and short stature in an individual with a mutation at the COL1A2 locus. Am J Hum Genet 51: 1396-1405.

28. Eggerding F.A., Schonberg S.A., Chehab F.F., Norton M.E., Cox V.A., Epstein C.J. (1994) Uniparental disomy for paternal $7 p$ and maternal $7 q$ in a child with growth retardation. Am J Hum Genet 55: 253-265.

29. Kondo I., Shimizu N. (1983) Mapping of the human gene for epidermal growth factor receptor (EGFR) on the p13-p22 region of chromosome 7. Cylogenet Cell Genet 35: 9-14.

30. Schinzel A., Frézal J., McKusick V.A. (1993) Report of the committee for clinical disorders, chromosome aberrations, and uniparental disomy. In Cuticchia AJ, Pearson PL, Klinger HP: Genome Priority Reports I: Chromosome coordinating meeting 1992: 658-669.

31. Ehrenborg E., Larsson C., Stern I., Janson M., Powell D.R., Luthman H. (1992) Contiguous localization of the genes encoding human insulin-like growth factor-binding proteins 1 (IGBP1) and 3 (IGBP3) on chromosome 7. Genomics 12: 497-502.

32. Miller S.A., Dykes D.D., Polesky H.F. (1988) A simple salting out procedure for extracting DNA from human nucleated cells. Nucleic Acids Res 16: 1215. 